\title{
Development of peripheral regions in the context of the bioeconomy paradigm
}

\author{
Yuliana Yarkova $^{1 *}$, Blaga Stoykova ${ }^{1}$, and Nedelin Markov ${ }^{1}$ \\ ${ }^{1}$ Department of Regional Development, Faculty of Economics, Trakia university, Stara Zagora, \\ Bulgaria
}

\begin{abstract}
The existence of peripheral regions is a significant challenge for regional development management. These regions have a specific economic and social profile, and their complex development is accompanied by the consideration of a number of factors that have a strong local significance and, in most cases, a dampening effect. The aim of the present study is to follow the trends in the development of a typical peripheral region in Bulgaria, focusing on identifying the potential of the regional economy for transformation to bioeconomic and circular orientation. The object of the study is the region Strandzha-Sakar, and the subject of the study is the potential for bio-economic and circular orientation based on specific traditional assessments, measuring both economic and demographic trends and local economic traditions.
\end{abstract}

\section{Introduction}

One of the permanent problems of the socio-economic development of a number of European regions is the continuing tendency of dominant relations in territorial development - "center-periphery". EU cohesion policy is expected to deliver results through national policies and programs, including targeted support for lagging regions. To date, the question is not simply whether national measures have the expected impact, but whether policy and practice priorities reflect current goals for tackling today's new challenges and technological advances.

The National Concept for Spatial Development 2013-2025 (NCSD) of the Republic of Bulgaria has set a goal for the transition from monocentric development to a moderate polycentric type of development, and the National Strategy for Regional Development 2012-2021 [1] indicates such priorities for support. However, the updated version of the NCSD [2] states that "after nearly seven years of implementation of the NCSD, the desired model of moderate polycentrism has not yet been fully achieved." In Bulgaria, there are significant differences among regions, both between the NUTS 2 regions and along the axis of urban-rural regions. This moves the attention to some horizontal policies, including those related to resource efficiency, environmental protection, and social inclusion. The interest in the regional level is provoked not only by the conspicuous inequalities at the level of the socio-economic indicators [3] of the Bulgarian regions, but also by the tendencies for

\footnotetext{
* Corresponding author: yuliyana.yarkova@trakia-uni.bg
} 
strengthening the territorial dimension of European policies. Of course, the ultimate goal is to transform the regional economy towards a more efficient, balanced and sustainable use of resources to achieve a circular, bio-oriented and smart economy, along with improving the quality of life of the local population and communities as a whole.

As most European strategies provide support in the field of the desired bioeconomy [4], so the Partnership Agreement of the Republic of Bulgaria (outlining the framework for management of European funds in Bulgaria in the programming period 2021 - 2027) reflects the five political European Union goals, one of which is "a greener, lower-carbon Europe - by promoting a clean and equitable energy transition, green and blue investments, circular economy, adaptation to climate change and prevention and risk management". The strategic framework document of our country, the National Development Program Bulgaria 2030 [5] includes as one of its leading priorities "Circular and low-carbon economy" in the second axis of development "Green and sustainable Bulgaria". Among the mentioned priorities is "Local development", which inevitably creates preconditions for linking all priorities to territorial context. One of the four pillars proposed in the draft of the National Recovery and Sustainability Plan is Green Bulgaria, with a focus on a circular and lowcarbon economy, sustainable agriculture, and biodiversity. Bulgaria has already approved a strategy related to one of the main bioeconomic sectors - Strategy for Strengthening the Role of the Agricultural Sector in Bioeconomy. The adoption of a Strategy and Action Plan for the transition to a circular economy of the Republic of Bulgaria for the period 20212027 and the elaboration of a National Strategy for Bioeconomy is forthcoming. The Innovation Strategy for Smart Specialization of the Republic of Bulgaria 2014-2020 [6] prioritizes an entire thematic area "Industry for healthy living and bio-technologies", but at a regional level there are few that reduce national priorities to identifying regional potential - North-Central region [7] (NUTS2 level), Sofia (LAU1) [8], Ruse (LAU1) [9], Plovdiv (LAU1) [10].

It should be added that the existing national strategy documents developed at an earlier stage need to be updated for a clearer and more defined policy, addressing the new challenges, and meeting modern environmental and socio-economic standards at a national and regional level.

The seventh report on economic, social and territorial cohesion "My Region, My Europe, Our Future" reports on the results of the cohesion policy in the EU's regions in recent years and assesses the impact of sectoral and national policies. One of the important conclusions from it is that despite the established reduction of regional disparities, they still remain significant between the central and peripheral and border areas. According to analyses by the National Center for Territorial Development, this also applies to the NUTS2 regions in Bulgaria in terms of the same statistical units in the EU, as well as between the regions in the country.

The NCSD 2013-2025 defines the territories with specific characteristics - the coastal territories (Black Sea and Danube), the mountain territories, the border territories, the territories at risk and the territories for landscape protection, natural and cultural values. The municipalities along the Danube and the Black Sea coastline have been identified and institutionalized with international strategic documents, the mountainous ones supported by the Rural Development Program, and the other categories still waiting for targeted support programs.

The National Strategy for Regional Development of Bulgaria (NSRDB, 2012-2022) has stipulated 152 municipalities for targeted support, using only two indicators - population in the municipality (less than 15 thousand) and the absence of a serious urban center (10 thousand) in the municipality. These municipalities have the character of peripheral rural areas, with low demographic potential, insignificant opportunities for economic development, with an unsatisfactory level of public service. Their remoteness from large 
cities and axes of development and communications strengthens their peripheral character. The Law on Regional Development, states "Designated areas for targeted support are a territorial basis for concentrating resources to reduce intra-regional disparities between the stages of development of individual municipalities and to achieve the goals of state policy for regional development." This allows for the development of targeted funding programs in peripheral areas. The expectations in 2015 to target funds for the peripheral regions in the country, one of which is Strandzha-Sakar, also one of the natural parks in Bulgaria, have not been realized (According to Ordinance №14 of April 1, 2003 of the Ministry of Health and the Ministry of Regional Development and Public Works in Bulgaria, those municipalities defined as rural areas are such that contain no settlement with a population of over 30,000 people. According to this criterion, 232 out of a total of 265 municipalities in Bulgaria are classified as rural. They cover $81.16 \%$ of the territory and $39 \%$ of the population).

The aim of the present study is to trace the trends in the development of this peripheral region in Bulgaria - Strandzha-Sakar, with a focus on identifying the potential of the regional economy for transformation towards bioeconomic and circular orientation.

Our thesis is that the periphery of a region not only does not limit the possibilities for transition of the business model from conventional to one that is the bearer of the circular and bio-concept, but it is necessary to seek and develop the potential for good practices, identifying the need for targeted support.

The subject of this study is to explore the potential for bio-economic and circular orientation on the basis of specific traditional assessments, measuring the economic and demographic parameters of the region.

The methods used include: quantitative methods of diagnostic analysis of objective statistical data, subjective and expert assessment of current practices, as well as a cabinet method for analysis and synthesis of accessible documentary information.

The object of the study is the Strandzha - Sakar region. Most of the territories in Strandzha-Sakar are characterized as low mountains, hills or hights. The arable land comprises $45.9 \%$ of the territory of Strandzha-Sakar and is one of the main resources of the region. Forests occupy $34.1 \%$ and meadows and pastures $-11.3 \%$ of the region. The highest share of arable land is in the municipalities of Sredets and Topolovgrad $(78 \%$ of agricultural land), followed by those in the municipality of Bolyarovo $(71,8 \%)$.

\section{General profile of the region}

The Strandzha-Sakar region is not an administrative unit but is informally defined and covers groups of municipalities with general specifics. As of 2019, there are 13 municipalities, 228 settlements (11 towns and 217 villages) in the region, with 160,230 people, representing $2.3 \%$ of the country's population on $7 \%$ of the territory of Bulgaria. More than half of the population lives in villages $-54.7 \%$ against $26.3 \%$ on average for the country, whereas with respect to 2007 the degree of urbanization has decreased by 3.6 percentage points, in contrast to the trends in the country, where urbanization for the period 2007- 2019 has increased by 3.0 percentage points.

The region is characterized by the lowest population density in the country (in 2019 only 21 people per sq. $\mathrm{km}$, compared to the national average of 62.6 people per sq. $\mathrm{km}$ ), the presence of many depopulated settlements, and aging population. This predetermines the socio-economic backwardness and the weak investment and entrepreneurial initiative.

All municipalities in the region of Strandzha-Sakar have the status of rural areas. (Disadvantaged are those areas in which the natural characteristics such as altitude, soil and climatic conditions, relief, etc. restrict, hinder, and increase the cost of agricultural production and are the reason for lower competitiveness of farmers working in them.). 
Moreover, the characteristics of the natural-climatic conditions and the soil resources in the considered municipalities meet the criteria for being defined as mountainous and disadvantaged areas. There are 15 mountain settlements from three municipalities - Malko Tarnovo, Tsarevo, Svilengrad. There are 90 settlements from all 13 municipalities in the region with characteristics other than the mountain ones.

Seven of the municipalities in the region are sparsely urbanized (in Haskovo district Topolovgrad municipality; in Burgas district - Malko Tarnovo, Primorsko, Sozopol municipalities; in Yambol district - Bolyarovo, Straldzha, Tundzha municipalities), and the rest are moderately urbanized. The cities in the region are of the fourth and fifth hierarchical level (In the NCSD 2013-2025 the group of towns-centers at the fourth hierarchical level are towns of micro-regional importance on the territory of groups of municipalities, the centers at the fifth hierarchical level are very small towns and villages, which are centers of municipal importance for the territory of the respective municipalities.). The fourth hierarchical level comprises Sozopol, Sredets, Tsarevo, Malko Tarnovo, Svilengrad, Harmanli, Topolovgrad. The fifth hierarchical level includes Primorsko, Bolyarovo, Straldzha.

Figure 1 shows that the population in Strandzha-Sakar has decreased throughout the whole period except for 2015, which can be defined as a conjunctural phenomenon associated with an increase in the mechanical growth of the registered inhabitants of some settlements in the region. The decrease is greater compared to the national trends - for the country the decrease is by $9 \%$ for the whole period of 12 years, and in the municipalities of Strandzha-Sakar region, this decrease is by $16 \%$. It is clear from the figure that the period of the global economic crisis has reflected on demographic trends - the rate of decline is accelerating. Although a reversal in the process was reported for the period 2012-2015, a new increase in population decline has been observed since 2016. Although the rate of decline in the last four years is twice as low as the rate of decline in the first four years of the twelve-year period, we cannot say that this is due to an improvement in the socioeconomic factors of the region.

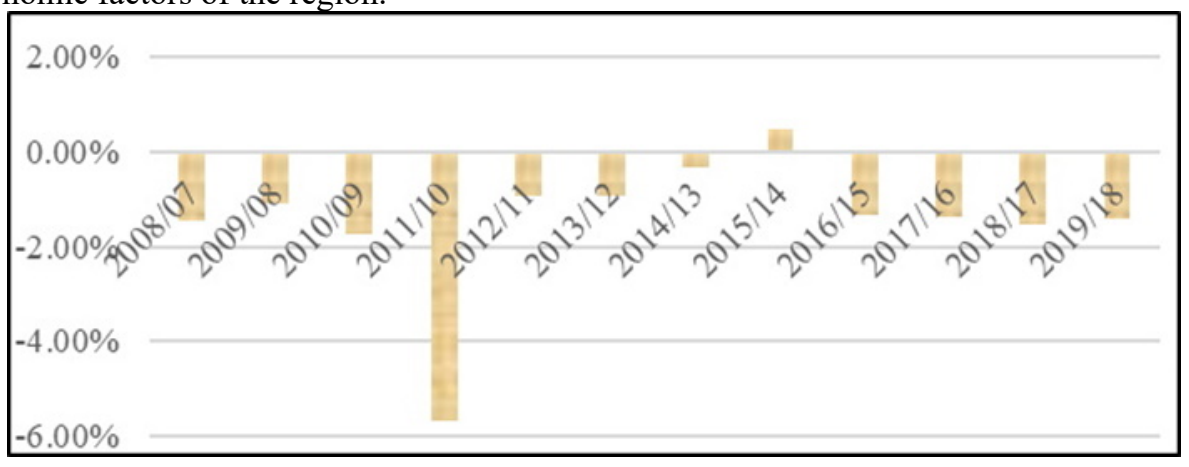

Fig. 1. Population growth rate 2007-2019

The mechanical movement, visible from Figure 3, is also the basis of the reported territorial structure. As indicated, in 2015 the rise of the inflow in Strandzha-Sakar is conjunctural, related to the local elections held in 2015 and a national referendum. However, we must note the fact that since 2016 there has been a clear shrinking of population from the region, which has slowed down as a process in the last two years of the observed period. The unexpected pandemic environment is likely to reverse the trend and make the relative mechanical growth positive. This is evidenced in the information about increased demand for housing in villages and small settlements in the country. 


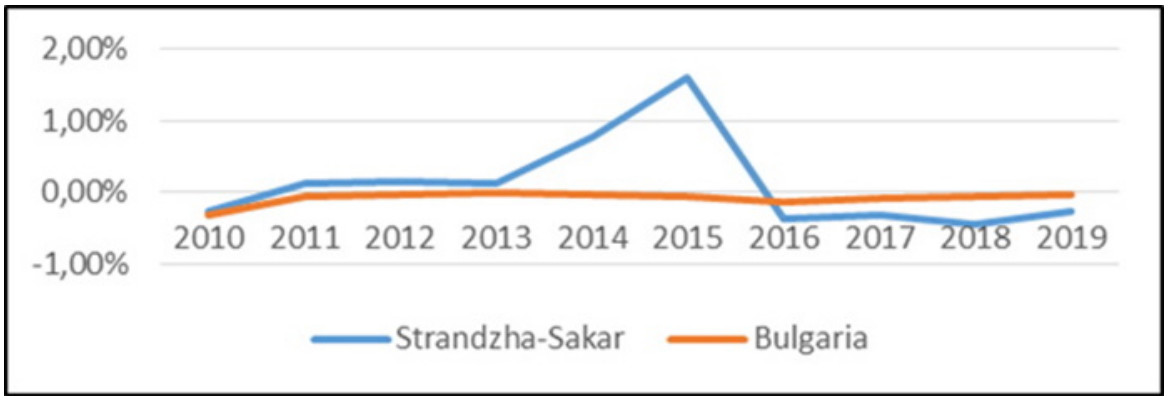

Fig. 2. Dynamics of relative mechanical growth (\%)

\section{Results of the study}

Table 1 shows the level of key economic indicators for the development of the StrandzhaSakar region

The main economic indicators lead to the conclusion that in general the economy in the municipalities of Strandzha-Sakar is poorly developed. Although according to the indicator Net sales revenue per capita the index compared to the level of the country is improving for the period 2007-2018, in the other two indicators the index is deteriorating - the level of wages continues to lag and even more unfavourable rates of unemployment are being formed.

Table 1. Main socio-economic indicators for Strandzha-Sakar region

\begin{tabular}{|c|c|c|c|c|c|c|}
\hline \multirow{2}{*}{ Region } & \multicolumn{2}{|c|}{$\begin{array}{c}\text { Average annual salary of } \\
\text { employees (BGN) }\end{array}$} & \multicolumn{2}{c|}{$\begin{array}{c}\text { Unemployment rate } \\
\text { as of 31.12. \% }\end{array}$} & \multicolumn{2}{c|}{$\begin{array}{c}\text { Net cash flow per capita as of } \\
\text { 31.12. thousands BGN }\end{array}$} \\
\cline { 2 - 7 } & $\mathbf{2 0 0 7}$ & $\mathbf{2 0 1 8}$ & $\mathbf{2 0 0 7}$ & $\mathbf{2 0 1 8}$ & $\mathbf{2 0 0 7}$ & $\mathbf{2 0 1 8}$ \\
\hline $\begin{array}{c}\text { Strandzha- } \\
\text { Sakar }\end{array}$ & 4368 & 9386 & 9,5 & 10,6 & 6,65 & 15,99 \\
\hline Bulgaria & 5167 & 13755 & 6,9 & 6,1 & 24,14 & 41,45 \\
\hline $\begin{array}{c}\text { \% vs. the } \\
\text { country } \\
\text { level }\end{array}$ & $\mathbf{8 4 , 5 \%}$ & $\mathbf{6 8 , 2 \%}$ & $\mathbf{1 3 8 , 2 \%}$ & $\mathbf{1 7 2 , 2 \%}$ & $\mathbf{2 7 , 5 \%}$ & $\mathbf{3 8 , 6 \%}$ \\
\hline
\end{tabular}

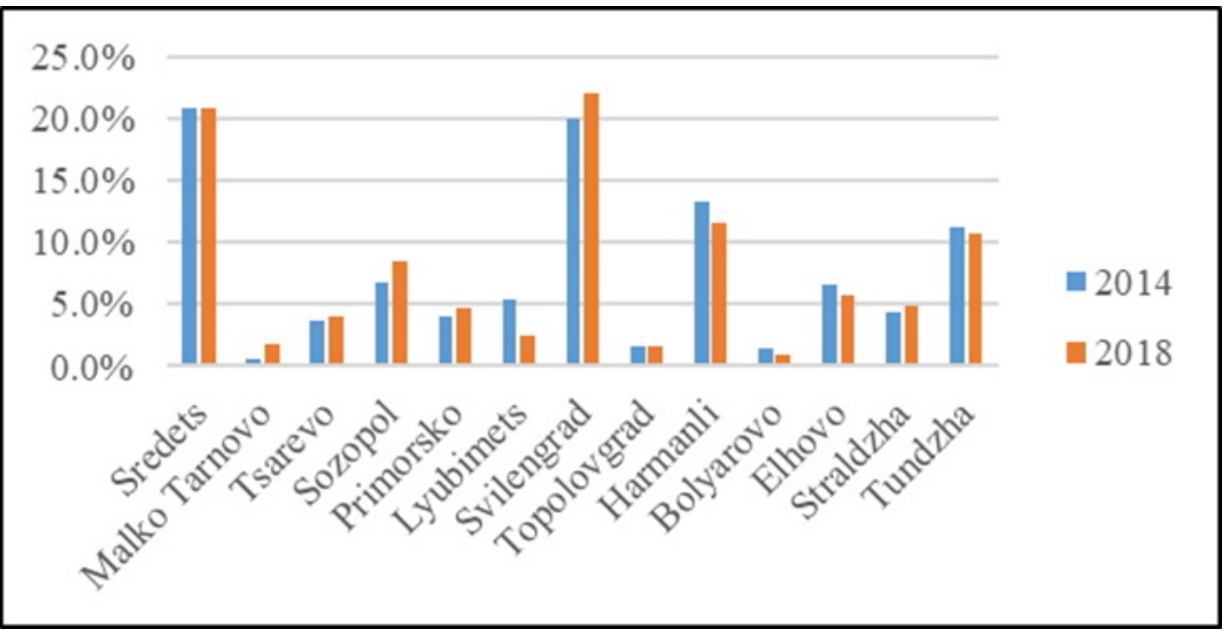

Fig. 3. Territorial structure (by municipalities) of the net cash flow in 2014 and 2018 
The territorial structure of the indicator Net sales revenues shows that the largest contribution to the economic results of the region belongs to the municipalities of Sredets, Svilengrad, Harmanli, Tundzha. All municipalities in the district of Burgas have shown a growth in the contribution to the economy of the region, which is understandable given the Black Sea tourist character of most of these municipalities. Out of four municipalities in Haskovo district, only Svilengrad municipality is characterized by an increase in the share of NCF in the region, while the other three have registered a decrease. In the same way, in the district of Yambol only in the municipality of Straldzha an increase in the share was registered, while in the others the contribution to the economy of the region has decreased.

The study also looks for some links between processes at a national and regional level. The reason for the study of such relationships is that there are complex relationships between national growth generators (banking and monetary policy, foreign investment, donor programs, investment projects, etc.) and the economic development of Bulgarian municipalities and regions. As a result of such a test, some regional disparities could be identified, explaining the pace and quality of regional growth.

A test was performed for the presence of a linear regression with an independent variable GDP in millions of BGN, and dependent variable the result value of NCF in thousands of BGN.

$$
\mathbf{N N P}_{\mathrm{p}}=\mathrm{a}_{0}+\mathrm{a}_{1} G D P_{\mathrm{n}}+\mathrm{E}
$$

Where:

$\mathrm{NNP}_{\mathrm{p}}$ - NNP at regional level

$\mathrm{GDP}_{\mathrm{n}}-\mathrm{GDP}$ at national level

E - error

$\mathrm{a}_{0}-$ constant

$\mathrm{a}_{1}$ - coefficient of the independent variable

The research hypothesis is that the positive development of the Bulgarian economy leads to an increase in the economic activity in the municipalities of Strandzha-Sakar region. There is also a null hypothesis that rejects the existence of such a relationship.

Although such a relationship seems too general, we report a statistically significant relationship (95\%) (positive and moderate) between the change in GDP at the national level and the NCF in the municipalities of Malko Tarnovo, Tsarevo, Sozopol, Topolovgrad, Harmanli and Elhovo. The analyzed data cover a 12-year period from 2007 to 2018. The existence of such statistical significance is a kind of contribution, because the period was accompanied by severe macroeconomic fluctuations caused by the global economic crisis of 2009. Table 2 and Figure 4 present a summary of the calculations made.

Table 2. Calculated data for possible statistical relationship for the independent variable NNPp

\begin{tabular}{|c|c|c|c|}
\hline Municipality & $\mathrm{R}$ & $\begin{array}{c}\text { Coefficient of the independent } \\
\text { variable }\end{array}$ & Sig. \\
\hline Malko Tarnovo & 0.74 & 0.0002 & 0.01 \\
\hline Tsarevo & 0,80 & 0.0001 & 0,001 \\
\hline Sozopol & 0,79 & 0,0002 & 0,002 \\
\hline Topolovgrad & 0,88 & 0,0001 & 0,001 \\
\hline Harmanli & 0,86 & 0,0001 & 0,003 \\
\hline Elhovo & 0,87 & 0,0002 & 0,002 \\
\hline
\end{tabular}

Figure 4 shows that there are alternating groups of 3-4 municipalities that show different rates of development. In the municipalities where a linear relationship has been found between the regional economic development and the complex economic 
development of the country, there are no disturbances in the economic tendencies. In contrast, in other municipalities such as Sredets, Bolyarovo, Straldzha, Tundzha, Lyubimets and Svilengrad no statistically significant relations were found. The reason for this is that regional shocks have been reported, namely in the period 2009-2012. For example, in the municipality of Sredets the NCF in 2010 compared to 2007 decreased by approximately $20 \%$, which is a strong cyclical decline. There is a decrease in economic revenues in Lyubimets municipality after 2015, Bolyarovo municipality after 2011, Tundzha municipality after 2015, etc. The harmonious development of some municipalities in unison with the pulse of the development of the national economy can only be a proof of the openness of some of the municipalities in the region.
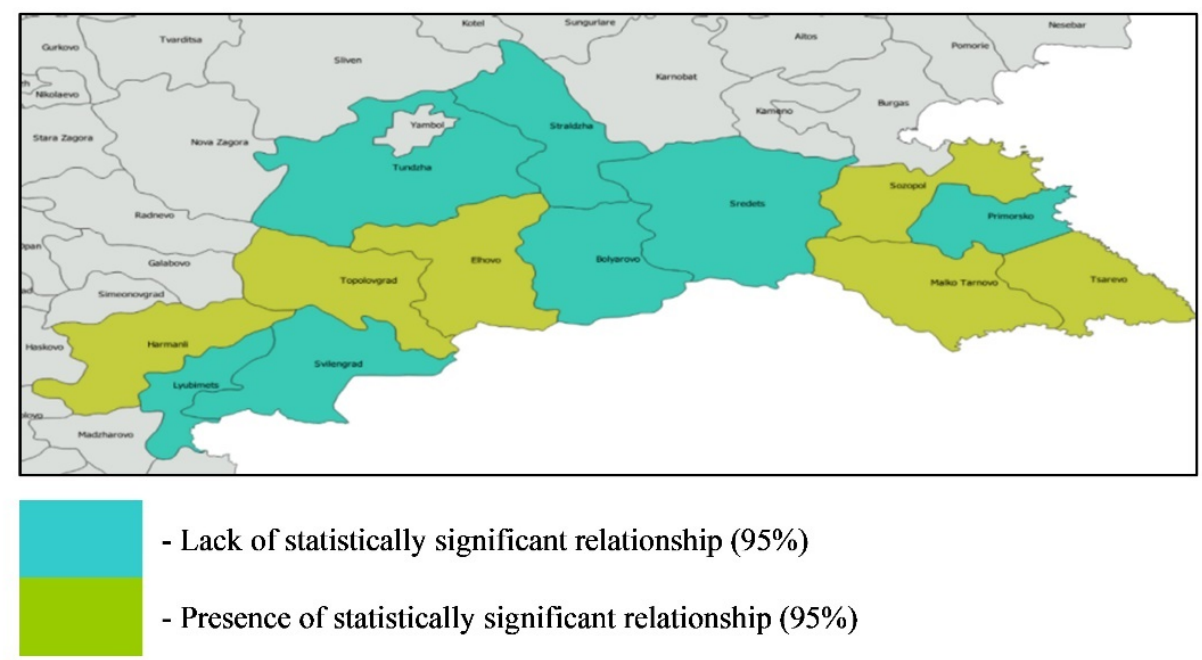

Fig. 4. Territorial structure (by municipalities) of the net cash flow in 2014 and 2018

Approximately in this central part of the region there are strong disruptions in the labor market during the economic crisis. The figures below show the unemployment rate. In the analyzed period, unemployment rose to levels that are extremely alarming. In some municipalities, such as Straldzha, the unemployment rate is three times higher than the national average. For the period 2007-2012, the core of unemployment is growing territorially. The tendency to have lower unemployment rates near the Black Sea coast and border checkpoints persists. This same core of unemployment (with few exceptions) shows a lack of linear links with national rates of development. By 2018, unemployment levels are starting to fall and return to normal levels for these municipalities. 


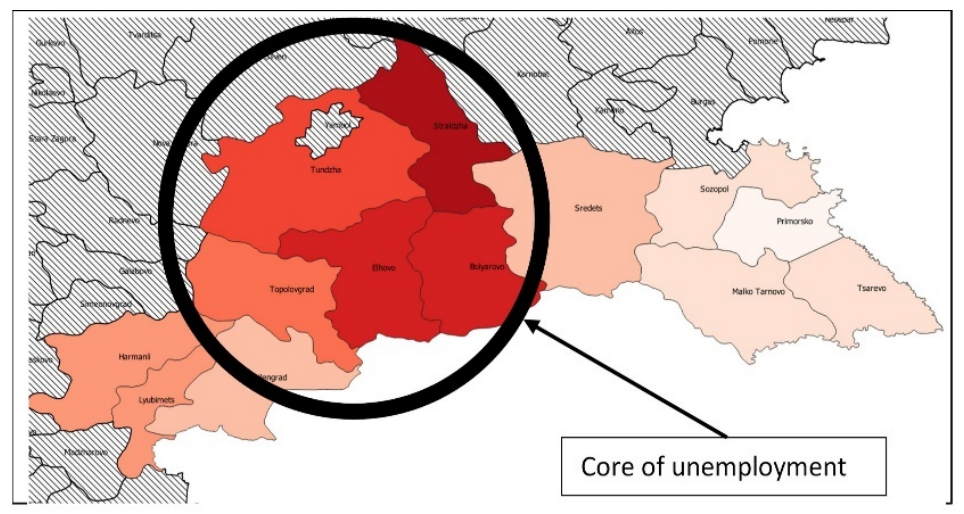

Unemployment - up to $10 \%$

Unemployment - $10-20 \%$

Unemployment - over $20 \%$

Fig. 5. Unemployment rate in 2007 (in\%)

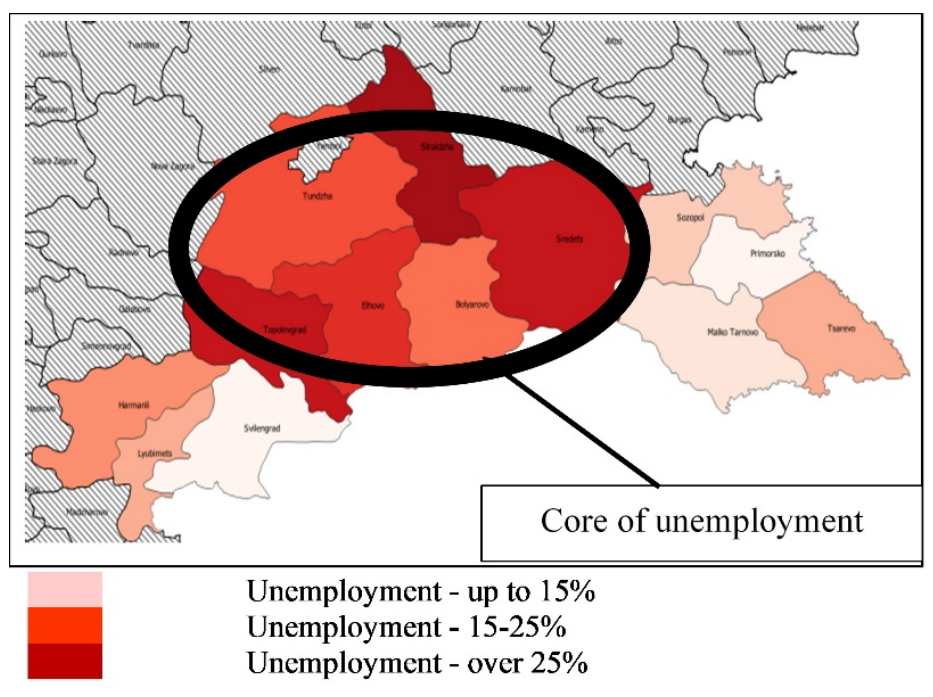

Fig. 6. Unemployment rate in 2012 (in\%)

\section{Limitations and opportunities for the economy based on bioeconomy in Strandzha-Sakar}

There are serious territorial limitations in the region. They arise not only from the proximity to state borders, but also in the presence of other circumstances. One limiting factor is the area for the conservation of biological diversity known as Natura 2000. At least half of the territory of the Strandzha-Sakar region falls within the scope of Natura 2000 (the territorial scope is presented in Figure 7).

The regulation of environmental legislation imposes many restrictions on almost all areas of economic activity. These limitations can be transformed into advantages. This can be done through the tools of bioeconomic orientation. 


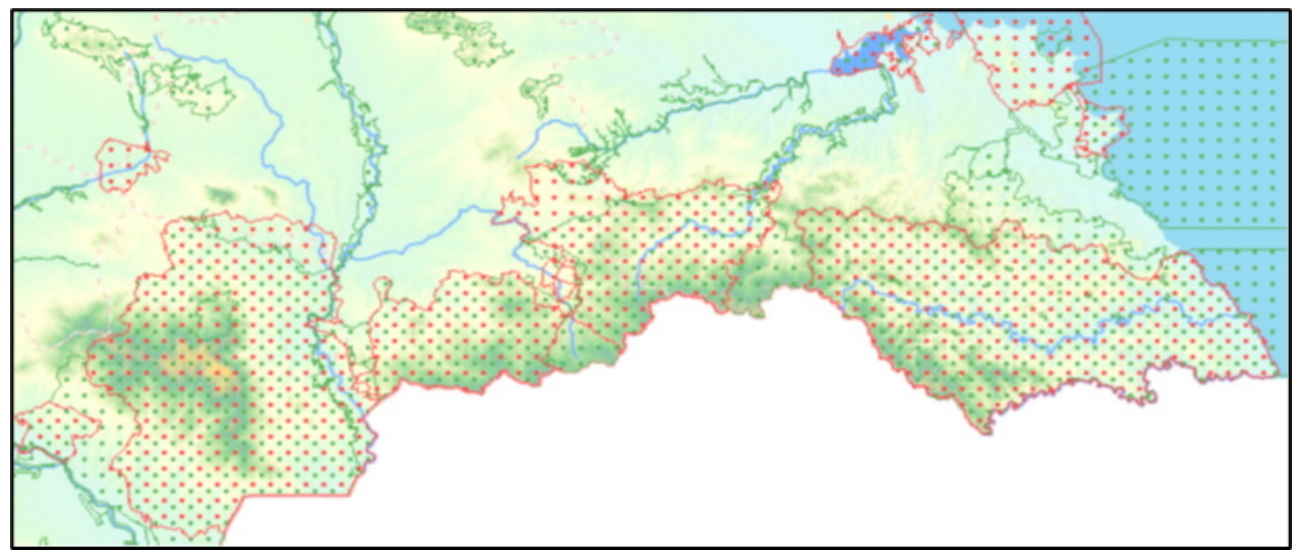

Fig. 7. Natura 2000 coverage in the Strandzha-Sakar region. With red dots - protected area of habitats, with green dots - protected areas for birds

For a long time, the definitive structural industries in the Strandzha-Sakar region have been the mining industry, machine building, garment, and food industries. But let us emphasize that about $40 \%$ of the population in the region is engaged in agricultural labor. It is dominated by small, poorly modernized agriculture, which should not be seen only as a disadvantage. This structure is an indicator of employment without a need for large investments. Even when they are not organic, they usually consume and offer natural agricultural and livestock products. Perennials such as vineyards, fruit trees and nut plants are minimal, and at the same time the conditions for their growth are very suitable. In recent years, the share of industrial crops (sunflower, rapeseed, coriander) has increased. On the territory of Strandzha-Sakar (Topolovgrad municipality) there is a bison farm with about 200 animals, which is considered the only one in Europe, and there is a pheasantry for breeding Colchis pheasant.

The food industry is ubiquitous and is represented by small companies mainly for the production of bread and bakery products. There is a real potential for restoring the traditions in the processing of agricultural products.

The unique combination of natural, cultural, and historical resources in the region assigns a high potential for tourism in its economic structure. The proximity to the Black Sea is also an advantage. The strategy for sustainable development of tourism in Bulgaria by 2030 envisages overcoming the seasonality of maritime tourism by combining it with other types of tourism - cultural, SPA, adventure. This provides the region with conditions to develop thanks to these alternative forms of tourism and to complement the Black Sea mass tourism. The strategy also indicates the hunting economic areas in Bulgaria, where resources for hunting tourism are available, as the Strandzha-Sakar region is one of them.

The natural resources that can be integrated in the bioeconomy sector are numerous Strandzha Nature Park, reserves, protected areas, rivers, rare habitats of birds and game. This allows the integration of resources into bioeconomy-oriented activities, whereas linking them to cultural traditions can restore old livelihood practices that contribute to the development of the region.

There is an understanding in scientific literature that "the decline of Strandzha is the result of national political and managerial mistakes that must be compensated." The analytical part of a scientific project developed in 2012 states that Strandzha region is one of the peaks of the "golden triangle" of the Thracian civilization and in ancient times was densely populated, as the landscape was modified for the needs of agriculture, animal husbandry and mining. The echo of the failure of the so-called "Republic of Youth" in the 1980 s is considered very resounding [11]. 
The targeted investment program (TIP) for targeted integrated development of the lagging regions in Bulgaria - Northwestern Bulgaria, Rhodopes, Strandzha-Sakar, border, mountain and semi-mountainous underdeveloped regions since 2014 indicates the opportunities for developing crop growing. It is noted that in the municipality of Topolovgrad there are favorable conditions for growing vines, nuts and sugar beets. Livestock breeding has a complementary function, as its development is focused on dairy cattle and sheep breeding, for which, in addition to the provided fodder balance, there are also significant areas that are constantly grassed (meadows) [12]. In fact, in StrandzhaSakar animal husbandry has deep roots. Sustainable development of the region is not possible without the revival of animal husbandry [13]. The primary branch sector of Strandzha-Sakar also includes picking - mainly mushrooms and herbs. Many herbs and medicinal plants are picked on the territory of Strandzha National Park. In recent years, nine species of herbs have been collected in an organized manner, mostly St. John's wort, as well as three types of berries. Revenues from the collection of herbs and medicinal plants are strongly influenced by market demand and climatic factors.

Very little is known about the traditional crafts in the Strandzha region, including for those who are mainly related to food processing. According to the archives of the Strandzha-Sakar Research Program, trade with forestry, agricultural and animal goods is developed in the region. Cheese making (yellow cheese and feta cheese) enjoys great popularity.

In 2019, an analytical report (in connection with research and good practices, innovative models in municipal cultural policy) related to the implementation of a project under OP "Good Governance", co-financed by the European Social Fund, describes good global practices, including business incubators and start-up support programs. Cultural practices from the Strandzha-Sakar region are also described, some of which are related to specific ethno-spaces [14].

Already in the first decade of the 21st century, the association "Business Center Elhovo" began the cultivation of herbal crops in order to create good conditions for the development of organic farming, including the cultivation of medicinal plants in the Strandzha-Sakar region. The work of the center is funded by a project from the Kingdom of Norway and UNDP, supporting the development of sustainable farms, providing sustainable income from herbal production and organic farming; production of quality products for the domestic market and export; application of modern agricultural practices in accordance with the environment and market requirements.

Scientists and experts in the field of growing medicinal plants have joined the work of the business center. An experimental field for the production of seeds and seedlings of species suitable for the region has been created. A base for drying, processing and packaging of the products has been built. It is a certified organic farm for herbs, spices and vegetables. The products can be found on the market under the brand "TRONKA". In the field of animal husbandry under the brand "Strandzha Sakar" in the village Stefan Karadzhovo beef and its derivatives are produced. The farm relies on values centered around quality and the environment.

Exactly those non-urbanized regions in which rural areas predominate are the most suitable for the development of bioeconomic activities, including the production of biomass fuels (without affecting protected tree species) and the production of energy from renewable sources. The lack of intensive human activities is a favorable environment for the development of alternative forms of tourism, which are extremely diverse. Small and medium-sized enterprises in the field of agricultural and food processing could develop with great success. All these opportunities go through the refinement of rural development policies, as well as the community-led local development approach, which allows crossfinancing of project initiatives. 


\section{Main conclusions and recommendations}

Despite the available potential for transformation of the economy in accordance with the objectives of the bioeconomic concept, the regional ecosystem of Strandzha-Sakar does not reflect the necessary environment for intensification of the desired processes. The following stand out: impossibility to carry out intensive agriculture, impossibility to conduct mass tourism, little investment in the development of the industry.

Leading sectors, the basis of the bioeconomic orientation in the Strandzha-Sakar region are agriculture, tourism, processing industry. The prospects are related to the development of bioeconomic activities, including the production of biomass fuels, as well as renewable energy sources, development of alternative forms of tourism, investments in SMEs working in the food industry [15].

The analysis of the logistical attempts to support the state so far shows that the right way is taken when the economic revival manages to become the basis of demographic stabilization. Of course, in the face of global challenges, attention must also be paid to measures that will create more opportunities and weaken the effects of visible threats.

It is crucial to overcome the dependence of the local population on external aid by supporting the local initiative, including through a number of legislative and financial mechanisms and instruments to support the absorption of resource potential. On the other hand, government incentives for small and medium-sized businesses from peripheral regions would lead to the establishment of the Strandzha regional brand. Particularly appropriate would be the support of clean eco-productions, the production of which could also enter the international market.

Some specific recommendations can be made for the use of bioeconomic orientation opportunities:

- Targeted government policy to stimulate disadvantaged and border regions - the central government should create a clear concept of how to support regions at risk. Strandzha-Sakar region is not the only one in Bulgaria. There are examples of such regions with systemic restraining factors elsewhere in the country.

- The preparation of a comprehensive regional strategy in the context of bioeconomy [16] can give impetus to the development of organic farming and environmentally responsible animal husbandry.

- Rural Development Policy 2021-2027 - with special focus: on the border regions, on the circular and bioeconomy. Emphasizing on the above-mentioned items is necessary to enable the formulated measures to achieve the goals of European and national strategies and policies.

- A new financial instrument for overcoming the risk in the field of bioeconomy and ensuring current liquidity - many of the policies in the field of regional development are supported by specialized funds for ensuring current liquidity in the implementation of projects. It is necessary to provide concrete funds that are focused on both rural development policies and the bioeconomic orientation of the region. This is important because investments in bioeconomic activities do not have a high rate of return due to low levels of profitability.

- Development of a network for education and consulting in the field of agriculture, production of energy from renewable energy sources, agro-energy and other economic activities, suitable for a region of the type Strandzha - Sakar. It is necessary to include a large set of institutions (including universities) to offer a comprehensive information and communication approach.

We wish to acknowledge the support of the National Scientific Program "Healthy Foods for Strong Bioeconomy and Quality of Life" of the Ministry of Education and Science, Bulgaria funding our work on developing the article. 


\section{References}

1. National Strategy for Regional Development of the Republic of Bulgaria 2012-2022

2. NCSD 2013-2025 update 2019, https://www.eufunds.bg

3. National Center for Territorial Development, Socio-economic analysis of the regions in the Republic of Bulgaria, 19 (2019)

4. National Scientific Program "Healthy Foods for a Strong Bioeconomy and Quality of Life", Analysis and profile of the state and potential for regional bioeconomy, (2020), http://uni-sz.bg/truni11/wp-content/uploads/biblioteka/file/TUNI10043236(1).pdf

5. The National Development Programme BULGARIA 2030, https://www.minfin.bg/en/1394

6. Innovative Strategy for Smart Specialization of the Republic of Bulgaria, https://www.mi.government.bg

7. Innovation strategy for smart specialization of the North-Central region 2015-2020, https://www.ruse.bg

8. Strategy for smart specialization of Sofia, https://www.sofia.bg

9. Innovation strategy for smart specialization of the Municipality of Ruse - 2016-2025, https://obshtinaruse.bg

10. Draft innovation strategy for smart specialization of the Municipality of Plovdiv, https://www.plovdiv.bg

11. Project "Cooperation for Biodiversity Conservation and Sustainable Local Development in the Strandzha Mountain", (2012), https://bbf.biodiversity.bg/en/Collaboration-for-Biodiversity-Conservation-andSustainable-Local-Development-in-Strandja-Mountain.p1245-y

12. Ministry of Regional Development and Public Works, Targeted investment program in support of the development of Northwestern Bulgaria, the Rhodopes, Strandzha Sakar, border, mountain and semi-mountainous underdeveloped regions, (2016), https://www.mrrb.bg/bg/regionalni-planove-za-razvitie-na-rajonite-ot-nivo-2-zaperioda-2014-2020-g-prieti-s-reshenie-na-ms/

13. Project "Cooperation for Biodiversity Conservation and Sustainable Local Development in the Strandzha Mountain", (2012), https://bbf.biodiversity.bg/en/Collaboration-for-Biodiversity-Conservation-andSustainable-Local-Development-in-Strandja-Mountain.p1245-y

14. Analytical report Conducting research on good practices, innovative models in municipal cultural policy, Project "Civil Society - the Subject of Local Cultural Policies", Sofia, (2019), http://bgregio.eu/media/files/Programirane\%20i\%20ocenca/OPRG\%2020142020_2014BG16RFOP001_1_3.pdf

15. D. Toteva, R. Popov, P. Marinov, TJS (to be published)

16. P. Branzova, Development of the regional bioeconomy in Bulgaria, in Proceedings of the Jubilee International Scientific Conference dedicated to the 100th anniversary of the University of Economics, 11-12 May 2020, 2,391-401, Varna, Bulgaria (2020) 